\title{
La Ciudad de México, cuna del primer estudio radiológico en la República Mexicana
}

\author{
Carlos Adrián De Alba-Guevara, ${ }^{1}$ Fernando De Alba-Quintanilla ${ }^{2}$ y Gustavo Casián-Castellanos ${ }^{3}$ \\ ${ }^{1}$ Departamento de Imagen, Hospital MEDISCIN, Ciudad Valles, San Luis Potosí; '2Centro de Radiodiagnóstico, Ciudad Valles, San Luis Potosí; \\ ${ }^{3}$ Secretaría de Salud, Hospital Juárez de México, Servicio de Radiología e Imagen, Ciudad de México. México
}

\begin{abstract}
Resumen
En agosto de 1896, el ingeniero Gilberto Crespo y Martínez publicó un artículo en el que presentó dos radiografías realizadas por Roberto Jofre y Fernando Ferrari Pérezen. Correspondieron a las dos primeras radiografías llevadas a cabo en la República Mexicana, dos meses antes de las efectuadas en la ciudad de San Luis Potosí el 24 de octubre y la del doctor Tobías Núñez en el Hospital Juárez, el 19 de octubre de ese mismo año.
\end{abstract}

PALABRAS CLAVE: Radiología. Historia de la Medicina. Avances tecnológicos en medicina.

\begin{abstract}
In August 1896, engineer Gilberto Crespo y Martinez published an article where he presented two radiographies produced by Roberto Jofre and Fernando Ferrari Perez. This corresponded to the two first radiographs carried out in the Mexican Republic, two months earlier than those produced in the city of San Luis Potosi on October 24 and the one by Doctor Tobías Núñez at the Juarez Hospital on October 19 that same year.
\end{abstract}

KEY WORDS: Radiology. History of Medicine. Technological advances in medicine.

\section{Introducción}

Roentgen descubrió los rayos $\mathrm{X}$ en noviembre de 1895 cuando se encontraba estudiando los misteriosos rayos catódicos. Para ello utilizó sencillos instrumentos que se podían encontrar en cualquier laboratorio de física o electricidad, por modesto que fuera, o que se podían adquirir fácilmente en los comercios por ser materiales de uso habitual. Así, con un sencillo tubo de Crookes, que tenía como fuente de energía eléctrica una bobina de Rumhkorff, y una pantalla fluorescente utilizada para identificar los rayos catódicos fuera del tubo, elaborada con una hoja de cartón recubierta por cristales de patino cianuro de bario, fue que descubrió los rayos $X$. Para evidenciarlos utilizó papel fotográfico común y obtuvo fotografías de varios objetos. ${ }^{1}$
El descubrimiento de Roentgen se publicó el 28 de diciembre de 1895 en el Boletín de la Sociedad Físico Médica de Würzburg, una modesta publicación. Envió separatas del artículo y fotografías a varios científicos (al parecer 90 cartas) y el 23 de enero del siguiente año presentó una conferencia en la Sociedad Físico Médica de Würzburg. La difusión del descubrimiento fue muy rápida y sin barreras, tanto que en 1896 se publicaron más de 1000 trabajos científicos y 48 libros sobre los rayos $\mathrm{X}^{2}{ }^{2} \mathrm{~A}$ México llegó la primera noticia mediante un telegrama cuyo texto apareció en el diario potosino El Estandarte. ${ }^{3}$

En ese momento era muy sencilla la construcción de un equipo para tomar radiografías y así lo entendieron rápidamente los físicos y aquellos con conocimientos de electricidad. Se requería una fuente de energía eléctrica, que podía ser proporcionada por
Correspondencia:

Carlos Adrián De Alba-Guevara

E-mail: carlosadrian@ hotmail.com
Fecha de recepción: 09-05-2017

Fecha de aceptación: 15-01-2018

DOI://dx.doi.org/10.24875/GMM.18003456
Gac Med Mex. 2018;154:527-531

Disponible en PubMed www.gacetamedicademexico.com 
una batería formada por varias botellas de Leyden interconectadas (la fuente de poder más elemental), una sencilla máquina electrostática, un generador eléctrico (como la bobina de Ruhmkorff), un dínamo de Piixi o directamente de la corriente eléctrica, ${ }^{4}$ así como un tubo al vacío con electrodos para generar corrientes de alto voltaje -el más empleado era el de Crookes, sin embargo, hacia 1986 se había construido una gran variedad de estos; en un artículo publicado por La Nature se ilustran 32 diferentes tubos de rayos $X^{-},{ }^{5}$ una pantalla fluoroscópica, que podía ser de fabricación artesanal o industrial como el criptoscopio, el esquiascopio de Magendie o el popular vitascopio de Edison. Finalmente, las imágenes se podían imprimir en papel fotográfico comercial o en cristales o celuloide recubierto de emulsión fotosensible de bromuro de plata. ${ }^{6}$

\section{Las primeras radiografías en la República Mexicana}

Sin lugar a dudas podemos afirmar que las primeras radiografías que se obtuvieron en la República Mexicana se practicaron en la Ciudad de México, sin que en este momento se pueda precisar el sitio, posiblemente en un gabinete de electricidad médica. Para afirmar tal suposición contamos con la fotografía de dos radiografías y el trabajo en el que se hace mención de este hecho. La historia de estas radiografías se pudo reconstruir gracias a un artículo rescatado en noviembre de 2016, en una librería de viejo localizada en Donceles, Ciudad de México.

Hasta ahora se había aceptado que los primeros estudios radiológicos y las primeras radiografías se realizaron en octubre de 1896 en la ciudad de San Luis Potosí y unos días después en el Hospital Juárez de México.

De acuerdo con el Oficial de San Luis Potosí, el 24 de octubre de 1896, en la ciudad de San Luis Potosí "[...] se han comenzado a hacer experiencias para ver a través de los cuerpos opacos...". De esos experimentos no quedó ninguna evidencia. El equipo había sido comprado en Berlín en fecha no precisada: era una "máquina de Roentgen" que de fábrica venía con una bobina de Ruhmkorff, un tubo de Crookes y un fluoroscopio de Edison.

Algunos reportes divulgados inicialmente por la prensa con frecuencia desvirtuaron su utilidad y sus usos; se llegó a creer que los rayos de Roentgen tenían aplicación en la fotografía ordinaria. El ingeniero Luis Espinosa y Cuevas, miembro de la oligarquía potosina y quien contaba con suficientes recursos económicos, adquirió una prometedora máquina de Roentgen por el equivalente a unos cien dólares para sus dos hermanos, quienes eran aficionados a la fotografía. La embarcó en algún puerto de Europa y la envío con destino a México. Llegó al puerto de Tampico el 3 de octubre de 1896 y, sin problemas aduanales de ningún tipo, fue remitida por ferrocarril a la ciudad de San Luis Potosí. ${ }^{8}$

Cuando el equipo de rayos $X$ se encontraba ya en la ciudad de San Luis, el señor Javier Espinoza y Cuevas, hermano de don Luis, empezó a realizar algunos experimentos fotográficos $\mathrm{y}$, en ocasiones, prestaba el equipo a algún médico selecto de la localidad. Así fue posible efectuar algún estudio radiológico médico.

La información anterior se publicó inicialmente en Archivos de Historia Potosina en junio de 1982 y posteriormente se publicaron varios artículos que difundieron información acerca de la aplicación de los rayos $X$ en diversas contingencias en la ciudad de San Luis Potosí. ${ }^{9-13}$ Curiosamente, de todas las experiencias mencionadas únicamente existe la radiografía no fechada, de un tobillo y pie con calzado, que se ha convertido un icono en la radiología y que en el artículo titulado "San Luis Potosí, cuna de la radiología mexicana" se describe como: "posiblemente la primera radiografía tomada en San Luis Potosí (y en la República), en el estudio de Espinosa y Cuevas, Hnos." Fue así como se aceptó que los primeros estudios radiológicos se realizaron en San Luis Potosí. ${ }^{14}$

Antes de 1982, la historia conocida señalaba que la primera radiografía en la república la había obtenido el doctor Tobías Núñez el 29 de octubre de 1896 en el Hospital Juárez de la Ciudad de México. Esto es descrito por el doctor Amador Zafra en su tesis "Algunas aplicaciones de los Rayos X a la cirugía y la Medicina", ${ }^{15}$ quien vivió de cerca el acontecimiento. La primera radiografía mostraba la luxación de un codo.

Esta fue la crónica que conocimos los radiólogos de la vieja generación y que se difundió en varios artículos relativos a la historia de la radiología, de consulta obligada por los interesados en el tema. ${ }^{16,17}$ Sin embargo, en la tesis del doctor Zafra hay un párrafo interesante:

\footnotetext{
...Sin entrar en grandes detalles, indicaremos rápidamente la técnica experimental empleada para producir los rayos $\mathrm{X}$. El material necesario consiste en una fuente de energía eléctrica, un transformador y un tubo de Crookes; la primera está formada
} 
generalmente por una batería de ocho a diez acumuladores que den una corriente de 16 a 20 volts; el transformador más usado es el carrete de Rumhkorff..., y en cuanto al tubo o ámpula radiográfica, los hay de muchas formas.... Esta es la disposición empleada en el Instituto de Electricidad Médica del Dr. Roberto Jofre...

El doctor Zafra deja clara la existencia de un equipo de rayos $X$ con el que se tomaban radiografías y se puede especular que la radiografía del codo no fue la primera que realizó. ${ }^{15}$

\section{Rectificando la historia}

Interesados en la historia de la radiología en México hemos investigado en numerosas bibliotecas públicas y privadas y otros muchos lugares. En una de las librerías de viejo de Donceles, en la Ciudad de México, en noviembre del 2016 nos encontramos un pequeño libro empastado en forma artesanal, en el que se incluye la separata de un artículo titulado "Sobre los rayos X" (Figura 1).

Este trabajo fue elaborado por el ingeniero Gilberto Crespo y Medina y leído en la Academia de Ciencias Exactas Físicas y Naturales, correspondiente de la Real de Madrid en agosto de 1896. En este artículo, el ingeniero Crespo y Martínez hace descripción completa del conocimiento que se tenía de los recién descubiertos rayos $X$, su manera de producirlos y los efectos fluoroscópicos y fotográficos. ${ }^{18,19}$ En la página 17 textualmente escribe:

\footnotetext{
...Esto en cuanto al origen, naturaleza y propiedades principales de los rayos $X$, y en lo que se refiere al modo de repetir las experiencias de Roentgen, nada más sencillo. Un tubo de Crokkes; un carrete de Ruhmkorff; una batería de bicromato y una placa fotográfica con una envoltura impermeable a la luz ordinaria, entre la cual y el tubo de Crookes debe colocarse el objeto cuya imagen se debe obtener. Con estos elementos sencillísimos los Profesores Fernando Ferrari y Roberto Jofre han obtenido entre nosotros las imágenes que me han hecho el favor de facilitarme y tengo el gusto de mostrar a vdes., de la mano del Dr. Jofre, de unas píldoras en el interior de una caja, de la grafita de un lápiz y de los cerillos encerrados en la caja respectiva...
}

México, agosto de 1896

La penúltima página del artículo corresponde a la fotografía de la radiografía de la mano del doctor Roberto Jofre, donde además se observan una caja de cerillos y un frasco de píldoras (Figura 2).

En la última página hay un collage con las fotografías del dibujo de un tubo de M. E. Colardeu y tres radiografías de varios objetos. Llama la atención una imagen repetida con la radiografía de varios objetos

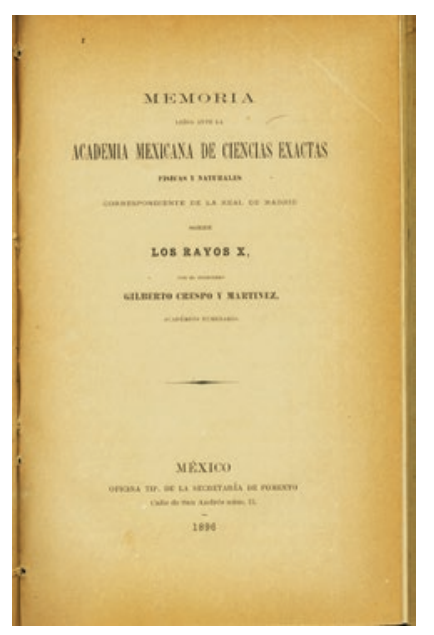

Figura 1. Portada del artículo del ingeniero Gilberto Crespo y Martínez titulado "Sobre los rayos X".

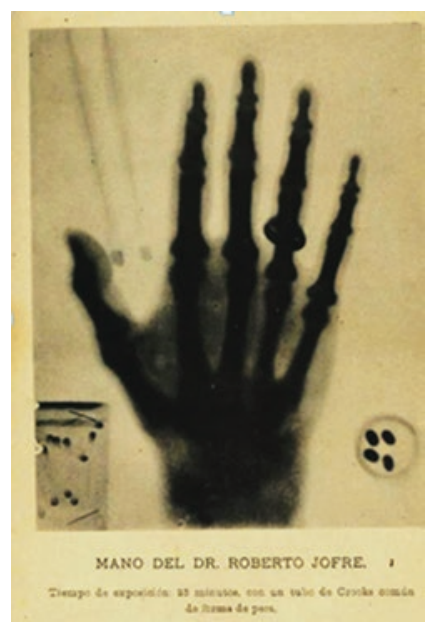

Figura 2. El pie de foto dice: "Mano del Dr. Roberto Jofre. Tiempo de exposición de 25 minutos, con un tubo de Crooks común de forma de pera".

(plumillas de manguillos, engranes) que fue realizada con dos tubos diferentes, uno de M. E. Colardeau y otro de Crookes, y entre las imágenes existe una diferencia notable en la nitidez (Figura 3). El ingeniero Crespo y Martínez señala que las radiografías fueron facilitadas por el ingeniero Fernando Ferrari Pérez y el doctor Roberto Jofre.

Al haber realizado la radiografía de un objeto con dos tubos de rayos $X$ diferentes, eso quiere decir que ya contaban con varios tubos.

Debemos concluir que si el doctor Jofre era quien se dedicaba a la electricidad médica, estos tubos eran de su propiedad y fue quien aportó el equipo de rayos $\mathrm{X}$ para estos experimentos, probablemente un equipo construido por él mismo. Suponemos que el ingeniero Ferrari Pérez, a quien le interesaba la fotografía, fue el encargado de revelar las radiografías. 


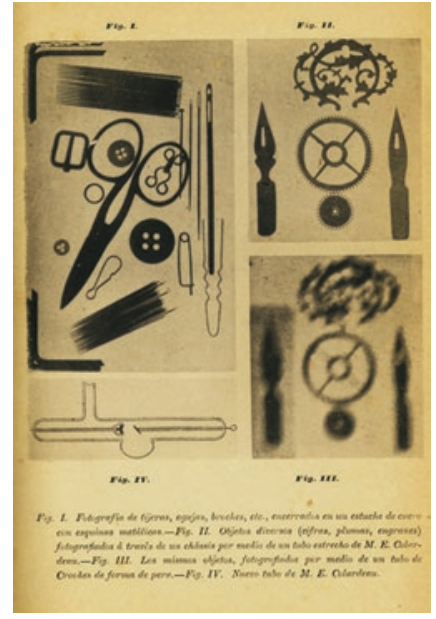

Figura 3. Segunda y última radiografía, en página no numerada, del artículo "Sobre los rayos X". En el pie de foto se lee: "Figura II. Objetos diversos (cifras, plumas, engranes) fotografiados a través de un chássis por medio de un tubo estrecho de M. E. Colardeau. Figura III. Los mismos objetos, fotografiados por medio de un tubo de Crookes de forma de pera".

Ahora sabemos que el ingeniero Gilberto Crespo y Martínez (1852-1916) nació en el puerto de Veracruz y realizó estudios en Xalapa, Puebla y finalmente en la Ciudad de México, donde terminó la carrera de Ingeniería en la Escuela Nacional de Ingenieros en 1879, especializándose en minas y metalurgia. Desde los inicios de su carrera empezó a trabajar en el Departamento de Agricultura, Minería y Comercio de la Secretaría de Fomento. El presidente Porfirio Díaz tenía interés de mostrar al mundo un nuevo rostro de México. Una de las medidas fue impulsar la ciencia, por lo que decidió fundar instituciones científicas y comisionó a diferentes profesionales para que acudieran y participaran en los principales congresos y concursos científicos internacionales, tratando de crear condiciones que permitieran que la comunidad científica aumentara sus conocimientos.

Las exposiciones internacionales se habían convertido en el escaparate de la modernidad, ahí se mostraba el vertiginoso avance de la ciencia y la tecnología. Díaz nombró al ingeniero Crespo y Martínez para que acudiera a la Exposición Internacional de Nueva Orleáns (1884), contactara con científicos de otros países y se pusiera al tanto del estado actual de la ciencia; no estaba por demás aprovechar la oportunidad de que los científicos tuvieran representación política. ${ }^{20-23}$

Durante su asistencia a la exposición en Nueva Orleáns, el ingeniero Crespo y Martínez fue nombra cónsul interino en La Habana y más tarde representante oficial de México en Cuba. En 1886 regresó a
México y empezó a participar activamente en la política y entre 1886 y 1902 fue diputado, representando a Veracruz. En 1889, como miembro de la Comisión Mexicana, asistió a la Exposición Universal de París y entre 1892 y 1899 estuvo en la cúpula del poder político, era Subsecretario de Fomento. ${ }^{9,11}$

El ingeniero Fernando Ferrari Pérez (1857-1933) era exalumno de la Escuela Nacional Preparatoria y de la Especial de Ingenieros, fue maestro de física y química, naturalista por vocación y fotógrafo por convicción. Inicialmente formó parte de la Comisión Geográfico-Exploradora perteneciente a la Secretaría de Fomento, cuyo objetivo original era preparar un mapa general de la república y organizar el conocimiento topográfico del país. Llegó a ser jefe de la Sección de Historia Natural de esta Comisión. En 1884, el gobierno ordenó a la Comisión participar en las exposiciones internacionales, como la de Nueva Orleáns, y Ferrari realizó cuidadosos catálogos zoológicos y numerosas reproducciones fotográficas de plantas y animales con las que formó una gran colección. Hacia 1887 se le nombró director del Museo Nacional de Plantas Mexicanas. Participó en las exposiciones de Nueva Orleáns, de París en 1889 y Chicago en 1894. ${ }^{24-26}$ Sin duda, en este trayecto estableció contacto con el ingeniero Crespo.

El doctor Roberto Jofre había realizados sus estudios en la Escuela de Medina de México y su examen profesional lo presentó en 1889; su tesis recepcional se titula Nuevo reóstato ${ }^{27}$ y se relaciona con la electricidad médica. Desde el inicio de su ejercicio profesional manifestó su interés por la electricidad aplicada a la medicina. Después de haberse titulado ingresó como ayudante (preparador) en el Instituto Médico Nacional, que hasta antes de 1888 se denominaba Instituto de Biología, cuya finalidad era realizar un inventario de la flora medicinal del suelo mexicano. Estaba adscrito a la Sección Tercera, o de Fisiología, que se encargaba del estudio de los efectos fisiológicos de las drogas producidas por las plantas medicinales. En el departamento de esa sección se realizaban las observaciones de toxicidad de las plantas, complementadas con estudios con aparatos electromédicos de registro: cardiógrafos, miógrafos, etcétera, que eran manejados por el doctor Jofre..$^{27-30} \mathrm{En}$ 1889 , el doctor Jofre publicó un trabajo titulado Nuevo reóstato, construido para obedecer el principio siguiente en las aplicaciones terapéuticas de la electricidad y años después, en 1893, El estudio de los reflejos, ambos publicados en la revista El Estudio. ${ }^{31}$ 
Las labores del Instituto estaban incorporadas o dependían de la Secretaría de Fomento.

Al parecer, fue así como se estableció contacto entre el variado grupo de científicos y políticos.

\section{Bibliografía}

1. Glasser O. Dr. W. C. Rontgen. EE.UU.: Charles C. Thomas Publishers; 1972.

2. Glasser O. Wilhelm Conrad Röntgen and the early history of the Roentgen Rays. EE.UU.: Norman Publishing; 1993.

3. Telegramas del extranjero. El Estandarte. 19 de febrero de 1896. Número 1657. Página 3.

4, Glasser O. The Science of Radiology. EE.UU,: Charles C. Thomas Publishers; 1933

5. Trevert $E$. Something about $X$ rays for everybody. The $X$ Rays Century. 1896;2:1:1-7.

6. Eisenberg RL. Radiology, An illustrated history. EE.UU.: Mosby Year Book; 1992.

7. Parte no Oficial. Crónica Local. Experimentos con los rayos X. Periódico Oficial del Estado de San Luis Potosí 24 de octubre de 1896;69: 9.

8. Alcocer AA, Padrón PF, Quijano PF. San Luis Potosí cuna de la radiología mexicana. Archivos de Historia Potosina. 1982;13:1-12.

9. Alcocer AA, Quijano-Y-Ramos, JM. Una aplicación de la radioscopia a la cirugía (entre1896 y 1899). Rev Med Hosp Central. 1978;2:36-38.

10. Alcocer AA. Datos para la historia de la radiología mexicana. Negatoscopio. 1985;1: 8-11

11. Alcocer AA, Padrón PF, Quijano PF. San Luis Potosí, cuna de la radiología mexicana. Biblioteca de Historia Potosina. Serie Cuadernos 87. Academia de Historia Potosina. San Luis Potosí, 1986.

12. Quijano PF, Quijano OF. Dos joyas bibliográficas médicas potosinas. Gac Med Mex. 1986;122:55-57.

13. Quijano PF, Padrón PF, Alcocer AA. Historia de la radiología. Un antecedente potosino de la arteriografía. Rev Mex Radiol. 1987;41:39-44.

14. Stoopen ME. Los pioneros de la radiología. En: Cárdenas-De-La-Peña E. Orígenes de las Especialidades en México. México: Academia Naciona de Medicina; 1993.
15. Zafra A. Algunas aplicaciones de los rayos $X$ a la cirugía y la medicina. [Tesis]. México: Escuela Nacional de Medicina de México; 1897.

16. Alcántara $\mathrm{HJ}$ ¿Quiénes introdujeron, en México, los rayos $X$ y el radio en medicina? Rev Med Mex. 1947:37:321-339.

17. Villanueva B. Datos para la historia de la radiología en México. Rev Mex Radio. 1969;23:259-274.

18. Crespo-Y-Martínez G. Sobre los rayos X. México: Oficina de la Secretaría de Fomento; 1896.

19. Crespo-Y-Martínez G. Sobre los rayos X. En: Datos para varios estudios recogidos por Gilberto Crespo y Martínez. Volumen IV. México: Secretaría de Fomento; 1899.

20. Camacho NE. Gilberto Crespo y Martínez y su participación en la política de fomento para el México porfirista. Reflexiones a propósito de su obra dedicada a Bélgica. Revista de Estudios Históricos. 2009; 49:131-168.

21. Rosenzweig G. Los diplomáticos mexicanos durante la revolución: Entre el desempleo y el exilio. Historia Mexicana. 2012;61:1461-1523.

22. Camacho-Navarro E. Gilberto Crespo y Martínez, un operador de la diplomacia de México en la Cuba republicana (1902-1906). Rev Mex Pol Ext. 2008;(84):93-120. Disponible en. https://revistadigital.sre.gob.mx/ images/stories/numeros/n84/camacho.pdf

23. Crespo y Martínez G. Datos para varios estudios. Volumen 3 México: Secretaría de Fomento; 1899.

24. Diccionario Porrúa de historia, biografía y geografía de México. Tomo I. México: Porrúa; 1986.

25. Enciclopedia de México. Tomo V. México: SEP; 1987.

26. Wikipedia. Fernando Ferrari-Pérez. Disponible en: https://en.wikipedia.org/wiki

27. Jofre Roberto. Nuevo Reóstato. [Tesis]. México: Escuela Nacional de Medicina; 1889.

28. Azuela LF, Guevara FR. La ciencia en México en el siglo XIX: Una aproximación historiográfica. Asclepio. 1998;50:77-105.

29. Hinke N, Chazaro L. El Instituto Médico Nacional. La política de las plantas y los laboratorios a fines del siglo XIX. México: Universidad Nacional Autónoma de México/Cinvestav; 2012.

30. Marcial-Avendaño A. Antecedentes del Instituto Médico Nacional y los primeros años de trabajo de la Sección $3^{\underline{a}}$ de Fisiología. Bol Hist Fil Med. 2007;10:21-27.

31. Rodríguez-De Romo AC. Fisiología mexicana en el siglo XIX: La investigación. Asclepio. 1997;49:133-145. 